\title{
Análise descritiva e comparação de curvas de precipitação em Diamantino, Mato Grosso
}

A chuva influência de maneira direta ou indireta vários processos sociais, econômicos e ambientais. Faz-se necessário o conhecimento do comportamento e da distribuição da precipitação pluvial de uma determinada região para um melhor planejamento sobre o uso desse recurso. Nesse sentido, este trabalho teve como objetivo a análise do comportamento da precipitação do município de Diamantino-MT por meio de parâmetros estatísticos descritivos e pela comparação do desempenho obtido com curvas de regressão polinomial e pela análise de Fourier. Para isso, foram utilizados dados médios mensais de precipitação pluviométrica entre os anos de 1998 e 2014 provenientes do Instituto Nacional de Meteorologia (INMET). Verificou-se que a precipitação média anual foi de 1951,2 mm com desvio padrão de $214,4 \mathrm{~mm}$, sendo os meses de fevereiro e março os mais chuvosos, e o mês de julho o mais seco. A estação chuvosa e a estação seca contribuíram, respectivamente, com $85,4 \%$ e $14,6 \%$ da precipitação total anual nesse período. Utilizando um procedimento de validação cruzada do tipo holdout com o teste de pareado de Wilcoxon obteve-se os níveis de significância de 0,785 e 0,551 para os modelos obtidos por Fourier e pela regressão polinomial, reportando a um melhor desempenho para o primeiro.

Palavras-chave: Parâmetros Descritivos; Regressão Polinomial; Fourier.

\section{Descriptive analysis and comparison of precipitation curves in Diamantino, Mato Grosso}

\begin{abstract}
Rain influences directly or indirectly several social, economic and environmental processes. It is necessary to know the behavior and distribution of rainfall in a given region for a better planning on the use of this resource. In this sense, this work had the objective of analyzing the precipitation behavior of the municipality of Diamantino-MT by means of descriptive statistical parameters and by comparing the performance obtained with polynomial regression curves and Fourier analysis. For that, average monthly rainfall data were used between 1998 and 2014 from the National Institute of Meteorology (INMET). It was verified that the average annual precipitation was of 1951,2 mm with standard deviation of 214,4 mm, with the months of February and March being the rainiest, and the month of July the driest. Rainy season and dry season contributed, respectively, with $85.4 \%$ and $14.6 \%$ of the total annual precipitation in this period. Using a holdout-type cross validation procedure and the Wilcoxon paired test, we obtained significance levels of 0,785 and 0,551 for Fourier models and polynomial regression, reporting a better performance for the first one.
\end{abstract}

Keywords: Descriptive Parameters; Polynomial Regression; Fourier.

Topic: Meteorologia, Climatologia e Mudanças Climáticas

Reviewed anonymously in the process of blind peer.

Luis Philippe de Arruda Lima

Universidade Federal de Mato Grosso, Brasil

http://lattes.cnpq.br/7860864484969573

luisphilippe@fisica.ufmt.br

Lauro Leocadio da Rosa

Universidade de Brasília, Brasil

http://lattes.cnpq.br/6296486218304982

lau.leo.ros@gmail.com

Silvino Mendes Garcia

Universidade Federal de Mato Grosso, Brasil

http://lattes.cnpq.br/3294052873036806

engmecgarcia@gmail.com

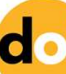

DOI: 10.6008/SPC2179-6858.2017.003.0017
Received: 08/03/2017

Approved: 09/05/2017

Referencing this:

LIMA, L. P. A.; ROSA, L. L.; GARCIA, S. M.; MUSIS, C. R.; GAIO, D. C.. Análise descritiva e comparação de curvas de precipitação em Diamantino, Mato Grosso. Revista Ibero-Americana de Ciências Ambientais, v.8, n.3, p.180-189, 2017. DOI: http://doi.org/10.6008/SPC2179-6858.2017.003.0017 


\section{INTRODUÇÃO}

O ciclo de evaporação das águas superficiais e a precipitação que a traz de volta à superfície é responsável pelo espalhamento da água no planeta Terra, mesmo sendo de maneira não uniforme (AYOADE, 1983; BARROS et al., 2011). Por isso, a chuva é um elemento de grande importância para caracterização de um clima de uma determinada região, bem como no manejo e uso apropriado desse recurso. A precipitação pluvial pode influenciar diretamente ou indiretamente a agropecuária, como a produtividade das culturas, por exemplo, age diretamente no abastecimento de água em rios e serve como auxílio na prevenção das queimadas, por isso, diante da sua grande influência, é imprescindível que se faça um monitoramento desse fenômeno (SILVA et al., 2003; SILVA et al., 2007; NUNES et al., 2016).

O estudo da variabilidade temporal da precipitação é importante para o entendimento do seu comportamento durante determinados períodos, o conhecimento dessa variabilidade dá suporte as atividades econômicas, sociais e ambientais (CANO et al., 2002). No Brasil, vários autores estudaram a variabilidade ou o comportamento da precipitação de uma determinada região por meio de parâmetros estatísticos descritivos.

Anjos et al. (2001) estudaram a precipitação pluviométrica de em Maringá/PR; Nery et al. (2002) também fez uso da estatística descritiva no estudo sobre a variabilidade da precipitação no Brasil Meridional; já Lima et al. (2008) investigaram a variabilidade da precipitação mensal em Alegre/ES; Silva et al. (2010) analisou a influência das multiescalas temporais na precipitação da Bacia do Rio Mundaú/AL com o uso do índice de anomalia de chuva e ondeletas; e Grigoletti et al. (2016) fizeram tratamento de dados climáticos para análise de desempenho térmico de edificações do município de Santa Maria/RS.

A precipitação no Mato Grosso, estado que se destaca no cenário nacional pela alta produção na agricultura, vem sendo comumente utilizada como objeto de estudo de diversos autores. Na última década, a estatística descritiva também auxiliou no entendimento da precipitação da região. Em destaque, Martins et al. (2010) e Dallacort et al. (2011) analisaram, respectivamente, a probabilidade e a distribuição das chuvas no município de Tangará da Serra entre 1970 a 2007. Para Cáceres, região do Alto Pantanal, Pizzato et al. (2012) avaliou distribuição e probabilidades de ocorrência a partir de uma série de dados de precipitação (1979-2009) e, para mesma cidade, Nunes et al. (2016) estudaram o comportamento da precipitação entre 1971 e 2011.

Além da estatística descritiva, os modelos numéricos de circulação geral da atmosfera (MCGAs) e os modelos regionais de escala espacial junto com desenvolvimento da modelagem dinâmica têm contribuído no diagnóstico e na prevenção de fenômenos meteorológicos de tempo e clima em todo o mundo (ALVES et al., 2007). Entretanto, ainda existem muitos lugares dos quais não se tem informação da quantidade de precipitação e para suprir essa necessidade utiliza-se a regressão polinomial na tentativa de obter estimativas de precipitação (GOMES et al., 2015).

Nessa linha de pensamentos, Gomes et al. (2015) utilizaram a regressão polinomial de grau 1 a grau 5, para estimar médias mensais de precipitação em locais conhecidos do estado da Paraíba/PB e comparálas com valores medidos em estações meteorológicas com a finalidade de verificar a precisão do método. 
Para detectar anomalias na distribuição da chuva em Bauru/SP, de 2004 a 2005, Emidio et al. (2008) utilizou a regressão polinomial de primeiro grau.

De forma mais sofisticada que a regressão polinomial, a análise de Fourier é uma ferramenta matemática convencionalmente utilizada no estudo da precipitação. Essa técnica considera que, em um intervalo de tempo finito, qualquer função analítica pode ser aproximada a função seno e cosseno (POLLOCK, 1999). Apesar de na origem ter como finalidade o auxílio a modelagem matemática da condução de calor, a aplicação desta se estende em vários ramos das ciências exatas, engenharias, ciência humanas e biológicas (BAZÃO et al., 2011).

Nogueira (2011) construiu cenários em relação aos regimes pluviométricos no estado do Ceará com a utilização da análise de Fourier e conseguiu resultados satisfatórios mostrando os padrões da variabilidade interanual. Diniz et al. (2008) modelou o comportamento do regime de precipitação com série de dados de 95 anos e 20 anos de Cuiabá e Santo Antônio do Leverger, cidades do estado de Mato Grosso, por meio também da análise de Fourier e comprovaram a existência de periodicidade no regime de precipitação nas áreas de estudo durante o período.

Nesse contexto, o objetivo deste trabalho foi analisar por meio dos parâmetros da estatística descritiva a variabilidade da precipitação na cidade de Diamantino/MT, entre os anos de 1998 e 2014, e comparar as curvas de dados estimados por regressão polinomial de grau 1 a grau 5, e pela análise de Fourier, com intuito de avaliar a adequação dos modelos para a região.

\section{MATERIAL E MÉTODOS}

\section{Área de estudo, aquisição e tratamento de dados}

O município de Diamantino, pertencente ao estado de Mato Grosso, e está a $209 \mathrm{~km}$ da capital Cuiabá. Localizada na Chapada dos Parecis, a cidade tem a agricultura como principal atividade econômica, considerada uma das maiores produtoras de soja do Brasil (RAMOS et al., 2015). Está presente nas coordenadas $14^{\circ} 24^{\prime} \mathrm{S}$ de latitude, $56^{\circ} 27^{\prime} \mathrm{W}$ de longitude e altitude de $286,3 \mathrm{~m}$ (DALLACORT, 2010). A classificação de Koppen é tipo Aw, com inverno seco e verão chuvoso. Os dados mensais de precipitação mensal acumulada, entre os anos de 1998 a 2014, foram obtidos por meio do Banco de Dados Meteorológicos para Ensino e Pesquisa (BDMEP) pertencente ao Instituto Nacional de Meteorologia (INMET) o qual possui uma estação meteorológica no município de Diamantino.

A análise da variabilidade mensal da precipitação se baseou nos seguintes parâmetros descritivos: média mensal de precipitação, desvio padrão e coeficiente de variação, conforme a equação abaixo. A análise coeficiente de variação baseou-se na classificação de Warrick et al. (1980) que considera CV menor que 12\% como baixa variabilidade, CV maior que $12 \%$ e menor que $60 \%$ como média variabilidade e CV maior que $60 \%$ como alta variabilidade. Tem-se $C V=\frac{S}{\bar{X}^{\prime}}$ onde $C V$, expresso em percentagem, é o coeficiente de variação, S é o desvio-padrão e $\bar{X}$ é a média.

Utilizou-se o método de Nery et al. (2002), que considera a contribuição da média de cada mês, em percentagem, em relação à precipitação média acumulada. $O$ valor limite de separação entre estação seca e 
chuvosa é de $8,3 \%$, ou $1 / 12$, do total anual de precipitação. Sendo assim, esse pode ser adotado na definição dos meses de seca e de chuva (NUNES et al., 2016). Também se utilizou o método de Lima et al. (2008) para definição das estações; nesse procedimento, trabalha-se com o valor médio mensal obtido da precipitação média anual acumulada como sendo o limite entre as duas estações, que no caso de Diamantino, para o período de 1998 a 2014, foi de 162,6mm, conforme se nota na tabela 1.

Além disso, foram desenvolvidas rotinas para obtenção de curvas pela regressão polinomial de grau 1 a grau 5, conforme Gomes et al. (2015), e Fourier, a partir da série temporal das médias mensais observadas. Para melhor detalhamento e compreensão serão descritos a seguir os valores dos parâmetros descritivos, predispostos na tabela 1, gráfico do percentual da precipitação mensal, ilustrado na figura 1, conforme Nery et al. (2002), e a representação da estação seca e chuvosa considerando a diferença do valor médio de cada mês pelo valor limite entre as duas estações segundo Lima et al. (2008), esboçado na figura 2.

Por fim, serão apresentadas em pares as curvas obtidas pela regressão polinomial e Fourier, representadas nas figuras 3 , 4 e 5 . Os modelos foram avaliados por procedimento do tipo holdout com $70 \%$ dos dados para calibração e $30 \%$ para teste utilizando o teste não-paramétrico pareado de Wilcoxon cujos valores de significância estão apresentados na tabela 2 .

\section{RESULTADOS E DISCUSSÃO}

A precipitação pluviométrica em Diamantino entre os anos de 1998 a 2014, manteve-se elevada nos meses de outubro a março, sendo no mês de fevereiro a maior quantidade, que representou $17,7 \%$ da precipitação total anual (Tabela 1). Os meses com menores valores de precipitação foram de abril a setembro, com o mês julho representando $0,3 \%$ da precipitação total anual, apontando a pouca ocorrência de precipitação nesse período. 0 mês de abril representou $6,9 \%$ precipitação total anual sendo $17 \%$ menor que o valor limite mensal de 162,6mm. 19.521,2mm foi o valor da precipitação média anual encontrada neste trabalho, sendo muito próximo ao valor de $1.815,5 \mathrm{~mm}$ encontrado por Dallacort (2010), que utilizou uma série de 1961 a 2008.

Tabela 1: Distribuição mensal do total médio da precipitação $(\mathrm{mm})$, valores extremos de precipitação (máximo e mínimo), coeficiente de variação (cv em \%) entre os períodos de 1998-2014 em Diamantino/MT.

\begin{tabular}{|c|c|c|c|c|c|}
\hline & Média & Mínimo & Máximo & Desvio Padrão & CV (\%) \\
\hline Janeiro & 324,3 & 94,1 & 520,4 & 128,0 & $39 \%$ \\
\hline Fevereiro & 349,3 & 150,1 & 531,6 & 110,6 & $32 \%$ \\
\hline Março & 286,5 & 157,3 & 638,3 & 117,9 & $41 \%$ \\
\hline Abril & 135,3 & 18,3 & 275,6 & 72,4 & $54 \%$ \\
\hline Maio & 40,0 & 6,4 & 172,5 & 40,6 & $102 \%$ \\
\hline Junho & 16,0 & 0,0 & 53,5 & 16,6 & $104 \%$ \\
\hline Julho & 8,5 & 0,0 & 42,8 & 15,0 & $176 \%$ \\
\hline Agosto & 15,4 & 0,0 & 97,8 & 25,5 & $166 \%$ \\
\hline Setembro & 72,0 & 0,0 & 195,7 & 52,2 & $73 \%$ \\
\hline Outubro & 185,9 & 57,7 & 314,8 & 76,6 & $41 \%$ \\
\hline Novembro & 228,6 & 67,5 & 409,9 & 75,6 & $33 \%$ \\
\hline Dezembro & 289,5 & 186,7 & 405,9 & 70,0 & $24 \%$ \\
\hline Ano & 1951,2 & 1647,9 & 2527,6 & 214,4 & $11 \%$ \\
\hline
\end{tabular}


Conforme a classificação proposta por Warrick et al. (1980), as maiores variabilidades dos dados ocorreram nos meses com menor quantidade de precipitação, CV maior que 60\%, corroborando com Silva et al. (2003), Lima et al. (2008) e Nunes et al. (2015). A ausência total de chuvas em alguns meses entre vários anos da série pode ser um dos motivos da alta variabilidade (SILVA et al., 2003; BLAIN et al., 2007). Os meses com média variabilidade foram de outubro a abril, com CV entre $12 \%$ e $60 \%$. Porém, a precipitação média anual apresentou CV menor que $12 \%$, isso se deve, possivelmente, ao fato de que ocorre compensação dos meses com menores volumes de chuva com os de maiores quantidades, mantendo assim uma baixa variabilidade (LIMA et al., 2008).

Sendo assim, a distribuição anual das chuvas no município de Diamantino se encontra entre níveis adequados ao desenvolvimento de culturas como a do pinhão manso, corroborando com Dallacort (2010). Dallacort (2010) se baseou em Gonçalves et al. (2008), e considerou a região como completamente apta para o desenvolvimento da cultura, pois a média anual de precipitação é adequada (acima 1000mm), e apresenta temperatura na faixa ideal, atendendo as propostas de exigências hídricas e de temperatura Henning (1996); Saturnino et al. (2005).

Os resultados obtidos neste trabalho se assemelham com os obtidos por Dallacort et al. (2011) para a cidade de Tangará da Serra, cidade presente na mesma região de Diamantino - médio norte do estado do Mato Grosso. Esse autor utilizou uma série histórica entre 1970-2007, e observou que os meses com maiores desvios padrões foram janeiro, fevereiro e março, cujos valores foram de 115, 107 e 110mm, respectivamente. Neste trabalho, observou-se também desvios-padrões de 128, 110,6 e 117,9 mm para os mesmos meses. Os valores 196 e 187,7mm de desvio padrão da precipitação anual foram encontrados por Martins et al. (2011) e Nunes et al. (2016) para a cidade de Cáceres, cidade situada na microrregião do Alto Pantanal distante $228,36 \mathrm{~km}$ de Diamantino, assemelhando com o valor encontrado neste trabalho que foi de $214,4 \mathrm{~mm}$.

Entre 1998 - 1999 e 1999 - 2000, anos de La ninã, a menor média observada neste trabalho foi do mês de junho, $0 \mathrm{~mm}$, e a maior foi de março com $298 \mathrm{~mm}$ de média e $92,6 \mathrm{~mm}$ de desvio padrão. Esse resultado encontrado foi próximo ao encontrado por Ramos et al. (2015), que analisou a precipitação pluvial na mesma cidade em anos de ocorrência de La niña, entre 1983 e 2003, e também observou que junho obteve a menor média, 9,94mm e desvio padrão de $15,4 \mathrm{~mm}$, e março a maior média $286,60 \mathrm{~mm}$ e desvio padrão 91,05mm.

Observou-se que, entre os anos de 1998 e 2014, os meses de outubro a março formaram uma estação chuvosa bem definida. Os meses de abril a setembro formaram a estação seca, pois o percentual e o valor médio de cada mês estiveram abaixo do proposto por Nery et al. (2002) e Lima et al. (2008), como demonstrado nas figuras 1 e 2.

Entretanto, o mês de abril pode ser considerado também como um mês de transição de estação chuvosa para seca nesse período, pois além de ter representado $6,9 \%$ da precipitação média anual acumulada, a variabilidade dos dados foi considerada moderada e o valor médio foi $17 \%$ menor que o valor limite entre as duas estações. Sendo não tão chuvoso quanto março (mês anterior) e não tão seco quanto 
maio (mês posterior), corroborando assim com Marcuzzo et al. (2011), que verificou que abril é um mês que antecede a mudança do comportamento hídrico estado de Mato Grosso. As estações chuvosa e seca representaram, respectivamente, $85,4 \%$ e $14,6 \%$ da precipitação total anual. Os maiores volumes ocorreram principalmente nos meses de fevereiro e março, o que pode gerar complicações na colheita da primeira safra de soja e na semeadura da segunda safra (RAMOS, 2015).

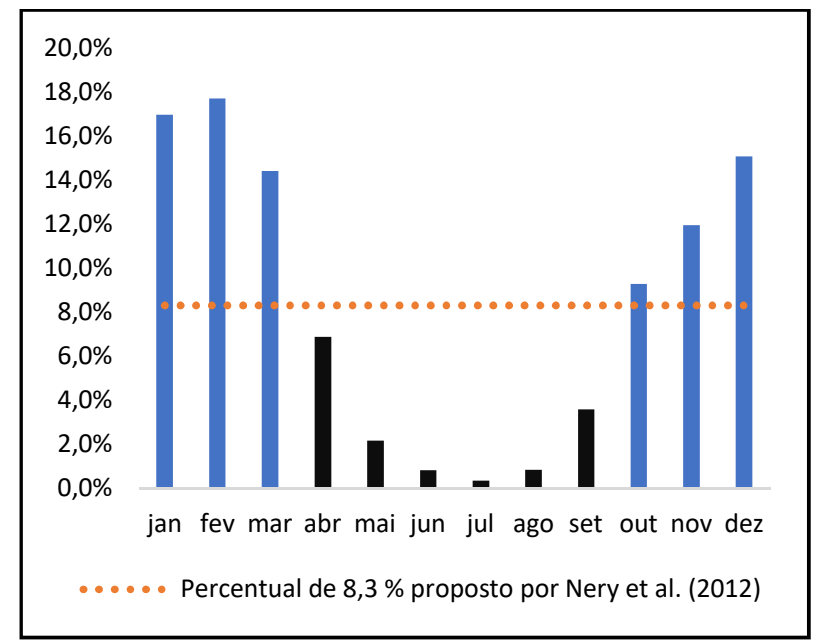

Figura 1: Percentual da precipitação mensal para o município de Diamantino/MT, no período de 1998 a 2014 . As barras em preto e azul correspondem aos meses de seca e de chuva.

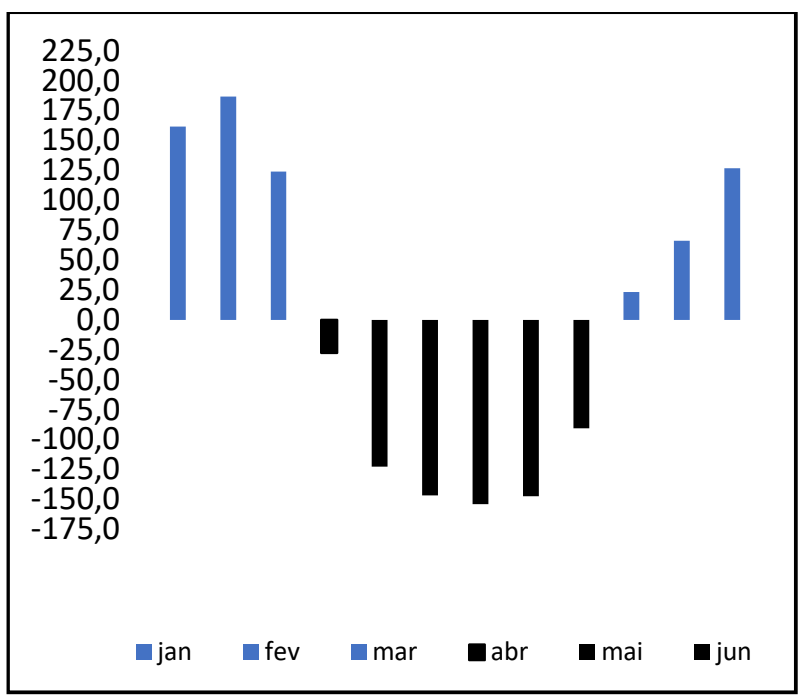

Figura 2: Representação da estação seca e chuvosa considerando a diferença do valor médio de cada mês pelo valor limite entre as duas estações, em milímetros, segundo Lima et al. (2008). As barras em preto, negativos, e azul, positivos, correspondem aos meses de seca e de chuva.

Os coeficientes de determinação das curvas obtidas pelas regressões polinomiais de grau 4 e 5 chegaram a valores consideráveis de $98 \%$ e $98,7 \%$, respectivamente, indicando que quanto maior grau da regressão melhor é o ajuste aos dados observados, conforme se predispõe na tabela 2, corroborando, assim, com Gomes et al. (2015), que obteve melhor ajuste aos dados observados de precipitação no estado da Paraíba utilizando regressão polinomial de maiores graus.

O coeficiente de determinação $\left(R^{2}\right)$ obtido neste trabalho para o modelo de Fourier, $99,1 \%$, foi próximo ao resultado encontrado por Andrade et al. (2006) que conduziu uma análise harmônica para dados entre 1921/1995 de precipitações médias mensais do município de Catolé de Rocha/PB, e obteve um modelo completo que explicou 99,6\% da variação total dos dados das precipitações durante esse período. 
Obteve-se os níveis de significância dos modelos utilizando um procedimento de validação cruzada do tipo holdout e o teste de pareado de Wilcoxon (Tabela 2). Para esse, o desempenho de Fourier foi melhor com nível de significância de 0,785 , seguido pelo modelo da regressão polinomial de grau 5 com nível de significância de 0,551. Assim sendo, o modelo obtido por Fourier teve um melhor desempenho para a região.

Tabela 2: Coeficientes de determinação $\left(R^{2}\right)$ e nível de significância dado pelo teste pareado de Wilcoxon.

\begin{tabular}{|c|c|c|}
\hline Modelo & $\mathrm{R}^{2}$ & Nível de significância (Wilcoxon) \\
\hline Polinomial Grau 1 & $6,2 \%$ & 0,109 \\
\hline Polinomial Grau 2 & $86,7 \%$ & 0,157 \\
\hline Polinomial Grau 3 & $87,9 \%$ & 0,218 \\
\hline Polinomial Grau 4 & $98,0 \%$ & 0,385 \\
\hline Polinomial Grau 5 & $98,7 \%$ & 0,551 \\
\hline Fourier & $99,1 \%$ & 0,785 \\
\hline
\end{tabular}

As figuras 3 e 4 mostram que os picos das curvas obtidas pelas regressões polinomiais de grau 1 a 3 não corresponderam com os dados observados, somente corresponderam as curvas das regressões polinomiais de grau 4 e 5 e por Fourier, sendo esse pico correspondente ao mês de fevereiro conforme a Tabela 1.

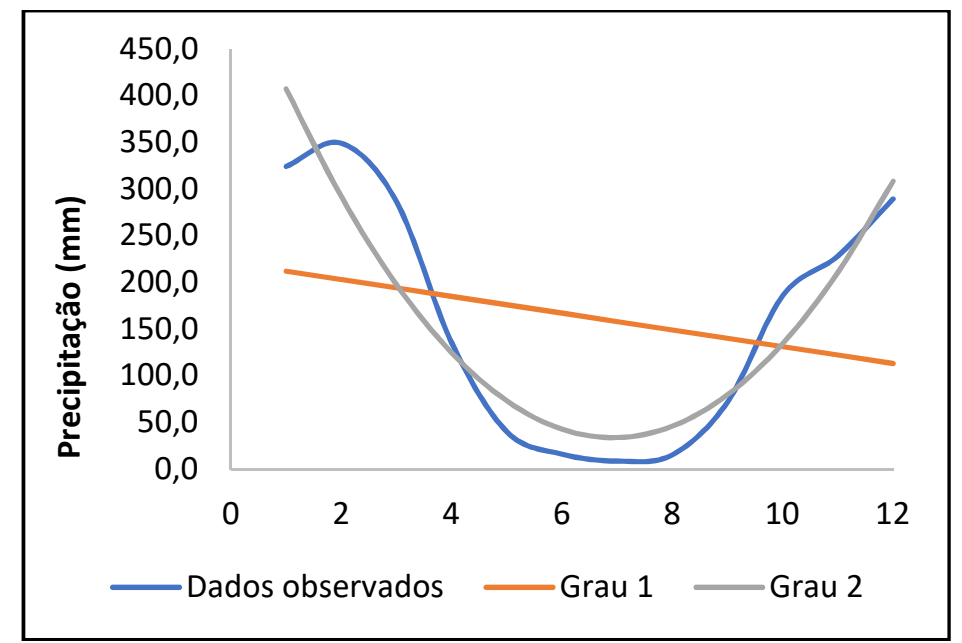

Figura 3. Curvas obtidas pelas regressões polinomiais de grau 1 a 3 e a curva dos dados observados de precipitação na cidade de Diamantino/MT entre período de 1998 e 2014. As coordenadas da abcissa, do 1 ao 12, representam os meses de janeiro a dezembro.

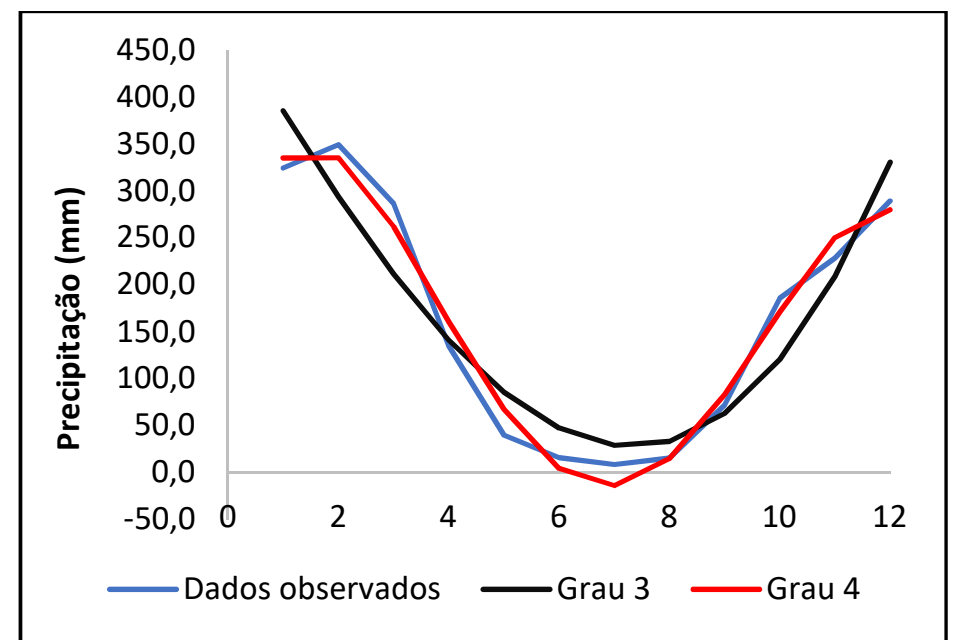

Figura 4. Curvas obtidas pelas regressões polinomiais de grau 3 e 4 e dados observados de precipitação na cidade de Diamantino-MT entre período de 1998 e 2014. As coordenadas da abcissa, do 1 ao 12, representam os meses de janeiro a dezembro. 


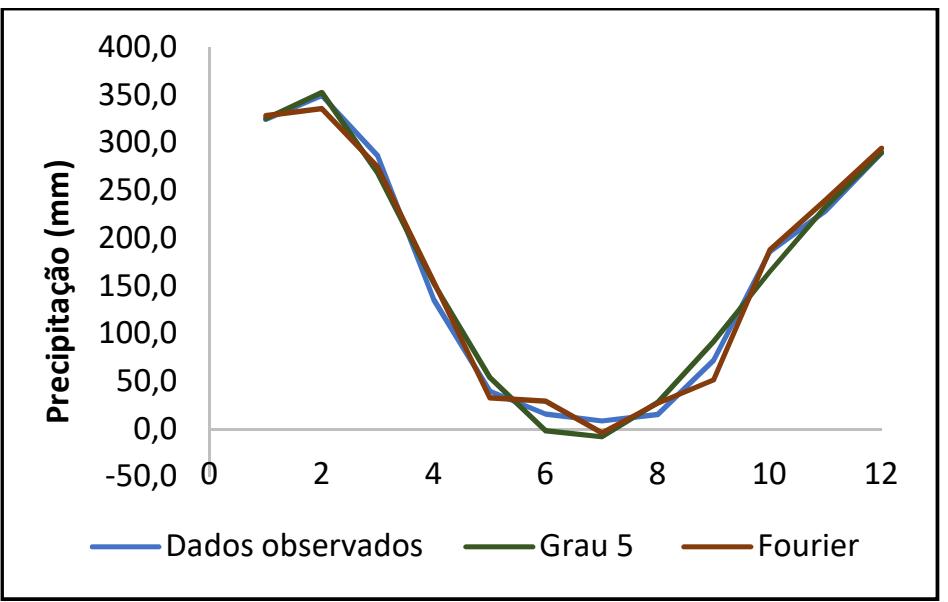

Figura 5. Curvas obtidas pelas regressões polinomiais de grau 5 e por Fourier e dados observados de precipitação na cidade de Diamantino/MT entre período de 1998 e 2014. As coordenadas da abcissa, do 1 ao 12, representam os meses de janeiro a dezembro.

Os vales das curvas obtidas por todos os métodos, exceto regressão de grau 1, coincidiram entre junho e agosto que são meses de seca. Entretanto, percebe-se que os valores estimados pelos métodos de regressões polinomiais de grau 4 e 5 e por Fourier, para o mês com menor quantidade de precipitação, foram negativos. Essa limitação pode ser explicada pelo fato de que nesse período existe uma maior probabilidade em acertos da não ocorrência de chuva, dessa forma, fica difícil a estimativa de chuvas esporádicas (PAZ et al., 2011). Além disso, alguns autores consideram o monitoramento da seca como complexo (QUIRING, 2009), sendo o menos compreendido entre todos os desastres naturais (HAGMAN et al., 1984).

\section{CONCLUSÕES}

A precipitação média anual em Diamantino, no período de 1998 a 2014 foi de 1951,2mm, com desvio padrão de $214,4 \mathrm{~mm}$. Destacaram-se os meses de fevereiro e março como sendo os mais chuvosos e o mês de julho como sendo o mais seco. Constatou-se, no município, nessa faixa de anos, a presença de dois períodos definidos: o período chuvoso, que vai de outubro a março; e o seco, que vai de abril a outubro, sendo abril o mês de transição do período chuvoso para o seco. A estação chuvosa e a estação seca contribuíram com $85,4 \%$ e $14,6 \%$ da precipitação total anual.

O modelo obtido pela série de Fourier ajustou-se melhor aos dados observados com $\mathrm{R}^{2}$ de $99,1 \% \mathrm{e}$ nível de significância de 0,785. Esses modelos podem servir como auxílio nas práticas agrícolas principalmente nos períodos chuvosos, já que na estação de seca pelo motivo da escassez de chuva e a presença de chuvas esporádicas, os métodos apresentaram valores negativos, sendo, então, um fator limitante.

\section{REFERÊNCIAS}

ALVES, J. M. B.; COSTA, A. A.; SOMBRA, S. S.; CAMPOS, J. N. B.; FILHO, F. D. A. D. S.; MARTINS, E. S. P. R.; MONCUNNIL, D. F.. Um estudo intercomparativo de previsão sazonal estatística-dinâmica de precipitação no nordeste do Brasil. Revista Brasileira de Meteorologia, v.22, n.3, p.354372, 2007.
ANDRADE, A. R. S.; PAIXÃO, F. J. R.; LEÃO, A. B.; AMARAL, I. G.. Análise harmônica no estudo das chuvas no Município de Catolé do Rocha-PB. Revista de Biologia e Ciências da Terra, v.6, n.1, p.56-58, 2006.

ANJOS, I. B.; MARTINS, M. L. O. F.; NERY, J. T.. Estudo da precipitação pluviométrica e balanço hídrico em 
Maringá. Boletim de Geografia, Maringá, v.19, p.45-58, 2001.

AYOADE, J. O.. Introdução à Climatologia para os Trópicos. Rio de Janeiro: Bertrand Brasil, 1983.

BARROS, M. P.; HASTEL, E. C.; CAMPOS, R. C.; ANJOS, S. L.. Estação meteorológica e sistema de captação e aproveitamento de água da chuva: Física Ambiental e Educação Ambiental integradas em uma única proposta. Ambiente \& Educação - Revista de Educação Ambiental, v.15, n.2, p.229-250, 2011.

BAZÃO, V. R.; MEIRA, S. A.; NOGUEIRA, J. R.. Análise de Fourier para o estudo analítico da equação da onda. Revista OMNIA Exatas, v.3, n.2, p.13-18, 2011

BLAIN, G. C.; PIEDADE, S. M. S.; CAMARGO, M. B. P.; GIAROLLA, A.. Distribuição temporal da precipitação pluvial mensal observada no Posto Meteorológico do Instituto Agronômico, em Campinas, SP. Bragantia, Campinas, v.66, n.2, p.347-355, 2007.

CANO, W.; BRANDÃO, C. A.. A Região Metropolitana de Campinas: urbanização, finanças e meio ambiente. Campinas: Unicamp, 2002.

DALLACORT, R.; MARTINS, J. A.; INOUE, M. H.; FREITAS, P. S. L.; COLETTI, A. J.. Distribuição das chuvas no município de Tangará da Serra, médio norte do Estado de Mato Grosso, Brasil. Acta Scientiarum Agronomy, v.33, n.2, p.193-200, 2011. DOI: http://doi.org/10.4025/actasciagron.v33i2.5838

DALLACORT, R.; MARTINS, J. A.; INOUE, M. H.; FREITAS, P. S. L.; KRAUSE, W.. Aptidão agroclimática do pinhão manso na região de Tangará da Serra, MT. Revista Ciência Agronômica, v.41, n.3, p.373-379, 2010.

DINIZ, G. L.; FONSECA, M.; CAMPELO JUNIOR, J. H.. Análise harmônica do regime de precipitação em duas localidades da baixada cuiabana. Biomatemática, v.18, p.37-48, 2008.

EMIDIO, Z. P. O.; LANDIM, P. M. B.. Análise de superfície de tendência aplicada à chuva, medida por radar meteorológico, nas regiões de Assis e Piracicaba, SP. Geociências, p.439-449, 2008.

GRIGOLETTI, G. C.; FLORES, M. G.; SANTOS, J. C. P.. Climate data processing for the thermal performance analysis of buildings in Santa Maria, RS. Ambiente Construído, v.16, n.1, p.123-141, 2016.

GOMES, M.; SANTOS, C.; SOUZA, F.; PAIVA, W.; OLINDA, R. I.. Análise comparativa da precipitação no estado da Paraíba utilizando modelos de regressão polinomial. Revista Brasileira de Meteorologia, v.30, n.1, 2015.

GONÇALVES, M. B.; SENTELHAS, P. C.. Zoneamento agroclimático do pinhão-manso no estado da Bahia, objetivando a produção de biocombustíveis. In: UNESCO; MBC; RECYT Mercosul; CNPq; PETROBRAS. Biocombustíveis para o Mercosul. Brasília: Ministério da Ciência e Tecnologia, 2008. p.121-140.

HAGMAN, G.; BEER, H.; BENDZ, M.; WIJKMAN, A.. Prevention better than cure: report on human and environmental disasters in the third world. Estocolmo: 1984.
HENNING, R. K.. Combating desertification: The Jatrophe Project of Mali, West África. Arilands Newsletter, n.40, 1996.

MARCUZZO, F. F. N.; MELO, D. C. R.; ROCHA, H. M.. Distribuição espaço-temporal e sazonalidade das chuvas no Estado do Mato Grosso. Revista Brasileira de Recursos Hídricos, v.16, n.4, p.157-167, 2011.

MARTINS, J. A.; DALLACORT, R.; INOUE, M. H.; SANTI, A.; COLETTI, A. J.. probabilidade de precipitação para a microrregião de tangará da serra, estado do Mato Grosso. Pesquisa Agropecuária Tropical (Agricultural Research in the Tropics), v.40, n.3, p.10-5216, 2010. DOI: http://doi.org/10.5216/pat.v40i3.6365

MARTINS, J. A.; DALLACORT. R.; INOUE, M. H.; GALVANIN, E. A. S.; MAGNANI, E. B. Z.; OLIVEIRA, K. C.. Caracterização do regime pluviométrico no arco das nascentes do Rio Paraguai. Revista Brasileira de Meteorologia, v.26, n.4, p.639-647, 2011.

NUNES, M. C. M.; SILVA, S. M. A.; NEVES, R. J.; NERY, J. T.. Comportamento da precipitação pluvial do município de Cáceres Pantanal Mato-Grossense no período de 1971 a 2011. Científica, v.44, n.3, p.271-278, 2016.

NERY, J. T.; MARTINS, M. L. O. F.; SANT'ANA, J. L. N.. Variabilidade da precipitação no Brasil Meridional. Acta Scientiarum Technology, v.24, p.1687-1695, 2002.

NOGUEIRA, M. L.. Construção de cenários de regime de chuvas no estado do Ceará: aplicabilidade de análise de Fourier. Dissertação (Mestrado em Engenharia Civil) Universidade Federal do Ceará, Fortaleza, 2011.

PAZ, A. R.; COLLISCHONN, W.. Avaliação de estimativas de campos de precipitação para modelagem hidrológica distribuída. Revista Brasileira de Meteorologia, v.26, n.1, p.109-120, 2011

PIZZATO, J. A.; DALLACORT, R.; TIEPPO, R. C.; MODOLO, A. J.; CREMON, C.; MOREIRA, P. S. P.. Distribuição e probabilidade de ocorrência de precipitação em Cáceres (MT). Pesquisa Agropecuária Tropical (Agricultural Research in the Tropics), v.42, n.2, p.10-1590, 2012.

POLLOCK, D. S. G.. A Handbook of Time-Series Analysis: Signal Processing and Dynamics. New York: Academic Press, 1999.

QUIRING, S. M.. Developing objective operational definitions for monitoring drought. Journal of Applied Meteorology and Climatology, v.48, p.1217-1229, 2009.

RAMOS, H.; DALLACORT, R.; SANTI, A.; QUEIROZ, T.. Pluvial precipitation in el niño, la niña and neutral years in diamantino, MT. Revista Brasileira de Meteorologia, v.30, n.1, p.71-80, 2015

SATURNINO, H. M.; PACHECO, D. D.; KAKIDA, J.; TOMINAGA, N.; GONÇALVES, N. P.. Cultura do pinhão-manso (Jatropha curcas L.). Informe Agropecuário, v.26, p.44-78, 2005.

SILVA, J. C.; HELDWEIN, A. B.; MARTINS, F. B.; TRENTIN, G.; GRIMM, E. L.. Análise de distribuição de chuva para Santa Maria, RS. Revista Brasileira de Engenharia Agrícola e Ambiental, Campina Grande, v.11, n.1, p.67-72, 2007. 
LIMA, L. P. A.; ROSA, L. L.; GARCIA, S. M.; MUSIS, C. R.; GAIO, D. C.

SILVA, J. W.; GUIMARAES, E. C.; TAVARES, M.. Variabilidade temporal da precipitação mensal e anual na estação climatológica de Uberaba-MG. Ciência e Agrotecnologia, v.27, n.3, p.665-674, 2003.

SILVA, D. F.; SOUSA, F. A. S.; KAYANO, M. T.. Análise da Influência das Multi-Escalas Temporais na Precipitação da
Bacia Hidrográfica do Rio Mundaú Através do IAC e Ondeletas: Baixo Mundaú. UNOPAR Científica Ciências Exatas e Tecnológicas, v.9, n.1, 2010.

WARRICK, A. W.; NIELSEN, D. R.. Spatial variability of soil physical properties in the field. In: HILLEL, D.. Applications of soil physics. New York: Academic Press, 1980. 